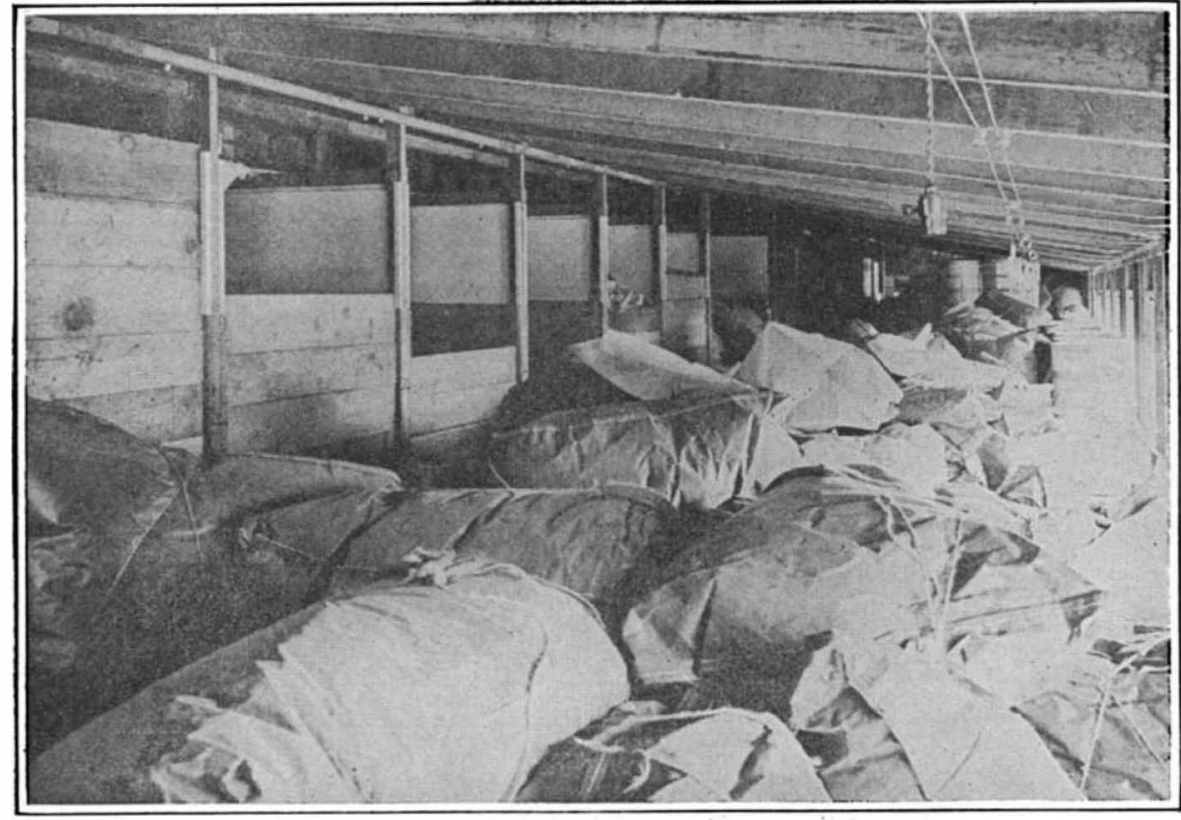

A storehouse filled with dried vegetables awaiting shipment

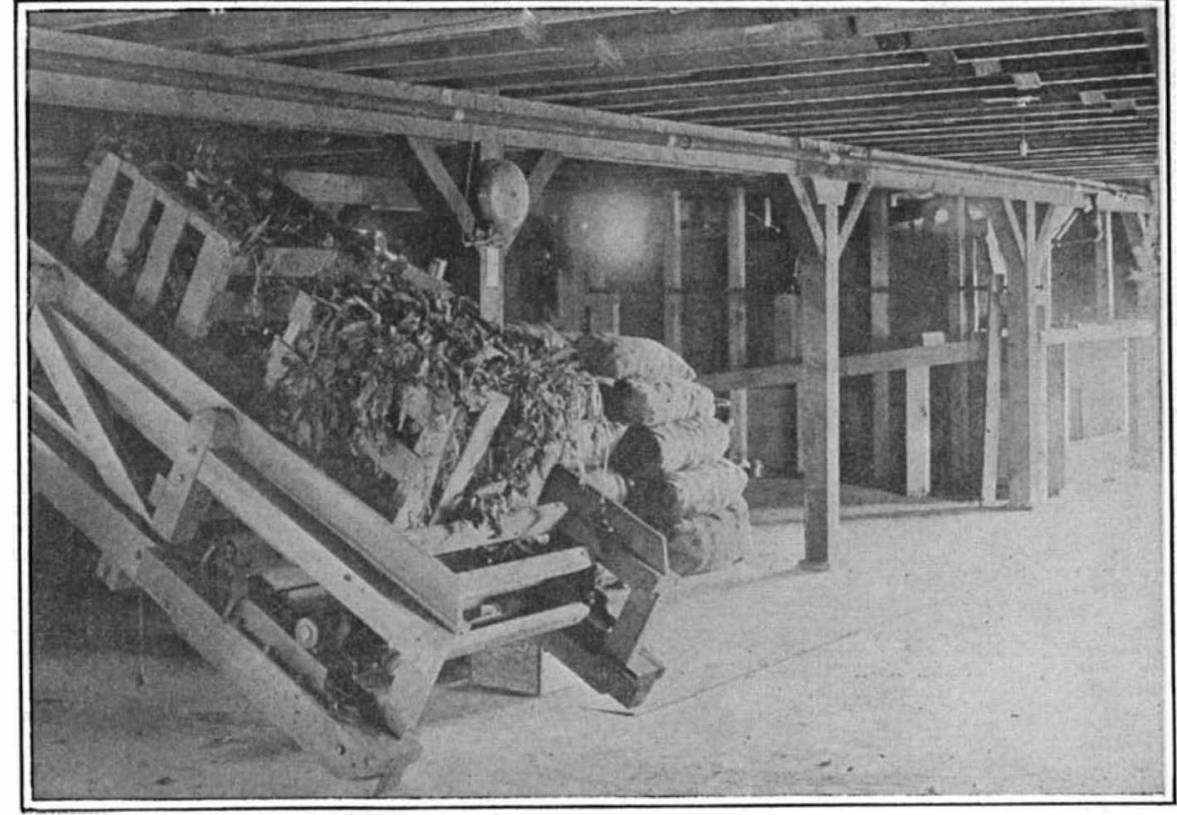

The conveyor that carries the fresh vegetables up to the preparing room

\title{
Dehydration Industry in America
}

\section{How It Is Carried On, and the Place It Holds in Our War Progress}

By E. Clemens Horst

FOSTERED by large Government contracts there is be of material permanent benefit to our economic life. This industry is the dehydration; or drying, of vegetables. By subjecting fresh vegetables to the action of circulating currents of warm, dry air the moisture content is exhausted with the result that the weight and bulk of the product is greatly reduced and the vegetable is made non-perishable and can be kept indefinitely. drying process; soaked in water for a few hours, the dehydrated product is restored to its original color, bulk and food qualities and when cooked it has the flavor and and food qualities and when cook

A year or two ago the dehydration of vegetables in this country was practically unknown of vegetables in this two small plants engaged in drying berries and vegetables but the bulk of their output was used in Alaska or distant places, where food supplies must be or other distant places where for light and and when our soldiers began and wher the the task of supplying enormous quantities Army in France, at a time when the demands upon world shipping were the most pressing in the history of the world. To solve the food problem the various departments of the Government coöperated and exhaustive tests were made of the different kinds of food available for export. The advisability of using dried vegetables was suggested, and a hearing on the subject was had before a sub-committee of the Senate Committee on Agriculture and Forestry, at which the food experts of the Department of Agriculture and the Food Commission appeared and testified as to the merits of the food. Representatives of commercial companies engaged in dehydrating vegetables were also heard, and the drating vegetables were also heard, and the writer appeared before the Committee California. Samples of dried vegetables California. Samples of dried vegetables were exhibited, and hundreds of pounds of Washington to be tested for flavor and food vashington to be tested for flavor and food served various vegetables cooked from deserved various vegetables cooked from defornia plants, and scores of Senators and fornia plants, and scores of Senators and Congressmen ate the food and were astonished at the similarity to the fresh. At the Reed
Hospital in Washington, 450 men were fed on the dried Hospital in Washington, 450 men were fed on the dried
vegetables, and it was found that five pounds of dried vegetables, and it was found that five pounds of dried stock supplied ample food for all. The President was made into soup, and many of the officials of the Governmade into soup, and many of the officials of

ment tried the samples in their own homes.
As a result of these tests the War Department entered As a result of these tests the War Department entered into contracts with several companies possessing the being enlarged as the industry develops and can take care of new demands. On the Pacific Coast, one organization alone now operates ten large commercial
driers, employing several thousand people, and large acreages have been contracted in the vicinity of the drying plants for the growing of vegetables. Million of pounds of dried potatoes, carrots, turnips and othe varieties have already been shipped to our armie abroad, and a steady stream of the new form of food speeds across the country and the Atlantic to satisfy the appetities of our boys over there. The American Red Cross has also become a large purchaser of dried vegetables for use in its rescue work in the devastated

regions, and in this country many of the large charitable institutions are becoming interested in the product for use in their work. The big shipping companies have on ocean vessels, because of the small space require for storage, and the keeping qualities and superior taste over canned goods. Scores of the finest hotels from New York to San Francisco now serve vegetables made from the dehydrated stock, and they report that the food is superior to that made from anything but ab solutely fresh produce. Many economies can be practiced by these large institutions in using dried vegetables, because all of the labor of preparing the food is eliminated. There is nothing to discard and no cleaning or washing of the vegetables is necessary, as all of this done at the drying plant. Dietitians of hospitals and food experts and chefs all unite in recommending the food.

When it is considered that from 65 to 85 per cent of the entire bulk and weight of green or fresh vegetables is water, and that it is the moisture that causes decay f ten true that the weight capacity of a boat is fully utilized without taking up all of the bulk.

The reason why so many hotels, hospitals and cafes are using dried vegetables is because of the convenience of the new food. A few cartons or tins of each variety of vegetable can be stored in a small space, and when de sired for use the only work involved is to place a few handsful in water to restore the moisture content. is required to soduce is unt a is required to sort the green stock, discarding wilted parts, tops or roots, and to wash the grit and dirt from the food. Even where the fresh vegetables are kept in refrigerated rooms, the loss through deterioration is excessive, and grown are lost before reaching cent of green

Vegetables used for drying are consumer. vicinity of the drying plants and are allowed to rediate vicinity of the drying plants, and are allowed to reach full ming from the field they are sorted and wa so after which them the feld they are sorted and washed, after which the the field they are sorted and was to various machines which peel, slice or otherwise prepare the
vegetables for the drying trays. Wherever possible machines are used instead of hand labor,
which insures absolute cleanliness and which insures absolute cleanliness and uniformity. The drying trays are taken ' top of aning rooms and arranged, one on top of anther, with open spaces on all throughout the rom, dry air circulating with the the rom woisture witho, slowly extracting the moisture without injuring the cell structure The ir is not allowed to et so product. The air is not allowed to get so hot that by a system of distribution the air is kept by a system of distribution the air is kept temperature throughout the room. When dried, the trays are taken to the packing dried, the trays are taken to the packing
room, and the food immediately placed in paper cartons, lined with waxed paper, or in large tin cans. Thus protected, the containers can be shipped to all parts of the world and the food will not be injured by excessive heat or cold.

to to go to waste, for all tops, peelings and waste portions from vegetables are fed to stock or hogs, and even the water used for washing the vegetables is saved and the
mineral salts found therein are mixed with mineral salts found therein are mixed with the greens fed to hogs.

The fan that forces the warm air into the drying room product is used, a wonderful saving can be effected in transportation, storage and handling. One pound of dried tomatoes or cabbage is equal to 20 pounds of the fresh or canned; one pound of spinach, when dried, is the equivalent of 18 pounds of the fresh, and so on down to potatoes, which have a ratio of one to six. One carton
of dehydrated tomatoes, weighing $21 / 4$ pounds, is equivaof dehydrated tomatoes, weighing $21 / 4$ pounds, is equivalent to a case of the canned containing two dozen quart
cans, the whole weighing 60 pounds. Therefore, in cans, the whole weighing 60 pounds. Therefore, in
shipping dried vegetables to our soldiers in France, the shipping dried vegetables to our soldiers in France, the
Government is able to furnish, in one shipload, as much Government is able to furnish, in one shipload, as much shiploads of canned goods. If we went a bit further and included the weight and bulk of the tin and wooden containers needed for the canned product, we should find a still greater saving, for in every car of canned vegetables the containers alone weigh about 24,000 pounds. While the dried vegetables furnished the Government are put up in tins, they are large enough to hold about ten pounds each, and two tins make up a crate light enough product anded by one man. The lightness of the dried capacity, whereas in the case of heavy canned goods it is
The expansion of the industry offers
remendous opportunities to this country. With a large commercial plant or tunities to this country. With a large nercial plant or a community plant in each locality, Thousands of acres of waste lands in the outskirts of cities, towns and villages can be utilized for the growing of vegetables, and the spaces between fruit trees in orchards can be used for the same purpose. Surplus market stocks can be taken to a nearby drying plant and aved, as is done in Europe. Germany has several thousand drying plants scattered throughout the country in which are dried all surplus vegetables grown, and before the war she annually dried twice as many potatoes as were grown for all purposes in this country. Her dehydrated vegetables have doubtless been one of the reasons why she has been able to withstand the food blockade of the Allies. England, Italy and France are also large users of dried vegetables, and in many communities the law requires that all fresh vegetables left over in markets at the end of the day shall be taken to drying plants. The feasibility of the new industry has been fully demonstrated, and the only thing remaining people to use the new form of food. 